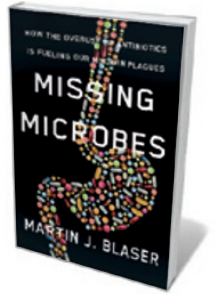

Missing Microbes: How the Overuse of Antibiotics is Fueling Our Modern Plagues MARTIN J. BLASER Henry Holt: 2014. lethal diseases. Antibiotics - like Caesarean sections and hand sanitizers - make modern life easier. Blaser would say that we have ignored Fleming's warning: we have consistently chosen convenient over smart and safe.

The first step, Blaser says, is to roll back antibiotic overuse in agriculture and medicine. After that, he suggests, we should bend our appetite for innovation towards finding ways to repair the microbiome damage that the wonder drugs have done.

Blaser foresees the development of microbial supplements - a more sophisticated version of the faecal transplants already being used in some quarters to combat Clostridium difficile infections that could restore microbial communities devastated by antibiotics. The regulation of faecal transplants has confounded the US Food and Drug Administration (M. B. Smith et al. Nature 506, 290-291; 2014), but many patients - along with academic researchers in Europe and Australia - have taken to them intuitively and enthusiastically. It seems likely that Blaser's concept of personal, protective microbial cocktails would also find support.

It is urgent that we take these steps soon. Missing Microbes explains that our ancient microbiome is akin to an essential organ; we unthinkingly excised it, and only now are waking up to the implications. Changes to it come with costs, Blaser warns, "but we are only just beginning to recognize them. They will escalate."

Maryn McKenna is the author of Superbug and Beating Back the Devil, and a senior fellow at the Schuster Institute for Investigative Journalism at Brandeis University. She lives in Atlanta, Georgia.

e-mail:mmckenna@mindspring.com

EDUCATION

\title{
Digital lessons learned
}

\section{Robert Lue enjoys a deft study of online pedagogy.}

$\mathrm{M}$ assive open online courses, or MOOCs, have generated unprecedented debate over their educational value and impact on the university ecosystem in the past three years. Deploying videos, online assessments and discussion forums to teach potentially 100,000 students at a time, MOOCs have taken off with the advent of for-profit companies such as Coursera in Mountain View, California, and non-profit efforts including edX, founded by Harvard University and the Massachusetts Institute of Technology (MIT) in Cambridge. As the faculty director of HarvardX, the Harvard initiative involved with edX, I have observed the pendulum of media opinion swing between extremes.

Initially MOOCs were lauded as the ultimate way to deliver educational content: they could reach the farthest corners of the globe and cut costs to promote sustainability. Now, views have reversed: the schemes seem to be reaching mainly those who already have a degree, and concerns are emerging that they will threaten faculty jobs in some institutions. The reality will almost certainly lie between.

In her provocative book The War on

Learning, Elizabeth Losh fires several warning shots across the bows of online education. Along with MOOCs, she takes on active learning methods such as realtime online polling. She provides welcome context on both the recent history of distance education, covering efforts such as the OpenCourseWare movement launched by MIT in 2002, and the surprising contribution of applications such as iTunes. Her book is a timely exploration of the sometimes daunting but often rewarding faculty and institutional experience of teaching with technology; it touches on students' experience more lightly.

Losh is critical of both irrational exuberance over the reach of technology, and panic that it has destroyed the classroom. She presents anecdotes documenting instructors' successes and failures, including her own misadventures using Twitter to engage a large lecture class in the Culture, Art and Technology programme at the University of California, San Diego. It became a platform for humorous expressions of student inattention and class-wide pranks. Indeed, not all modes of digital engagement are suited to education: anonymous mass action can result solely in mischief. Losh seeks a pedagogical silver lining by connecting classroom Twitter with new ways for students to engage with both content and the learning experience.

Losh's rich selection of anecdotes swerves between triumphs and tragedies - so much so that real success becomes difficult to recognize. She seems to revel in this ambiguity, perhaps seeking to underscore just how much remains unproven and unsettled in a field still finding its way. Is the compelling but carefully scripted drama of a TED Talk a model for engaging students online - or an opportunity for mutual narcissism, whereby the speaker tells the audience exactly what they want to hear? Does the professor lauded for his or her classroom oration promote selfinterest above learning when their online reach goes global?

Healthy scepticism is Losh's dominant tone, especially in her discussion of 'gamification' - the use of video-game $>$

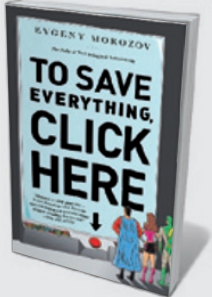

To Save Everything, Click Here: The Folly of

Technological Solutionism Evgeny Morozov (PublicAffairs, 2014)

Can a toolbox of techno-fixes really solve climate change, disease and crime? Social theorist Evgeny Morozov rebels against a technocratic Utopia and critiques the ideology of computerized cure-alls. (See Nicholas Carr's review: Nature 495, 45; 2013.)

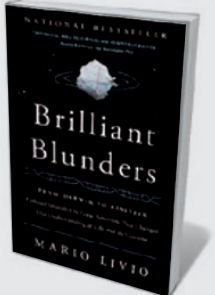

Brilliant Blunders: From Darwin to Einstein Mario Livio (Simon \& Schuster, 2014) Astrophysicist Mario Livio reveals the epic errors of famous scientists that yielded glorious breakthroughs. When Einstein misconstrued universal equilibrium, his equations led to the discovery of the expanding cosmos. (See Mario Livio's Comment: Nature 497, 309-310; 2013.) 


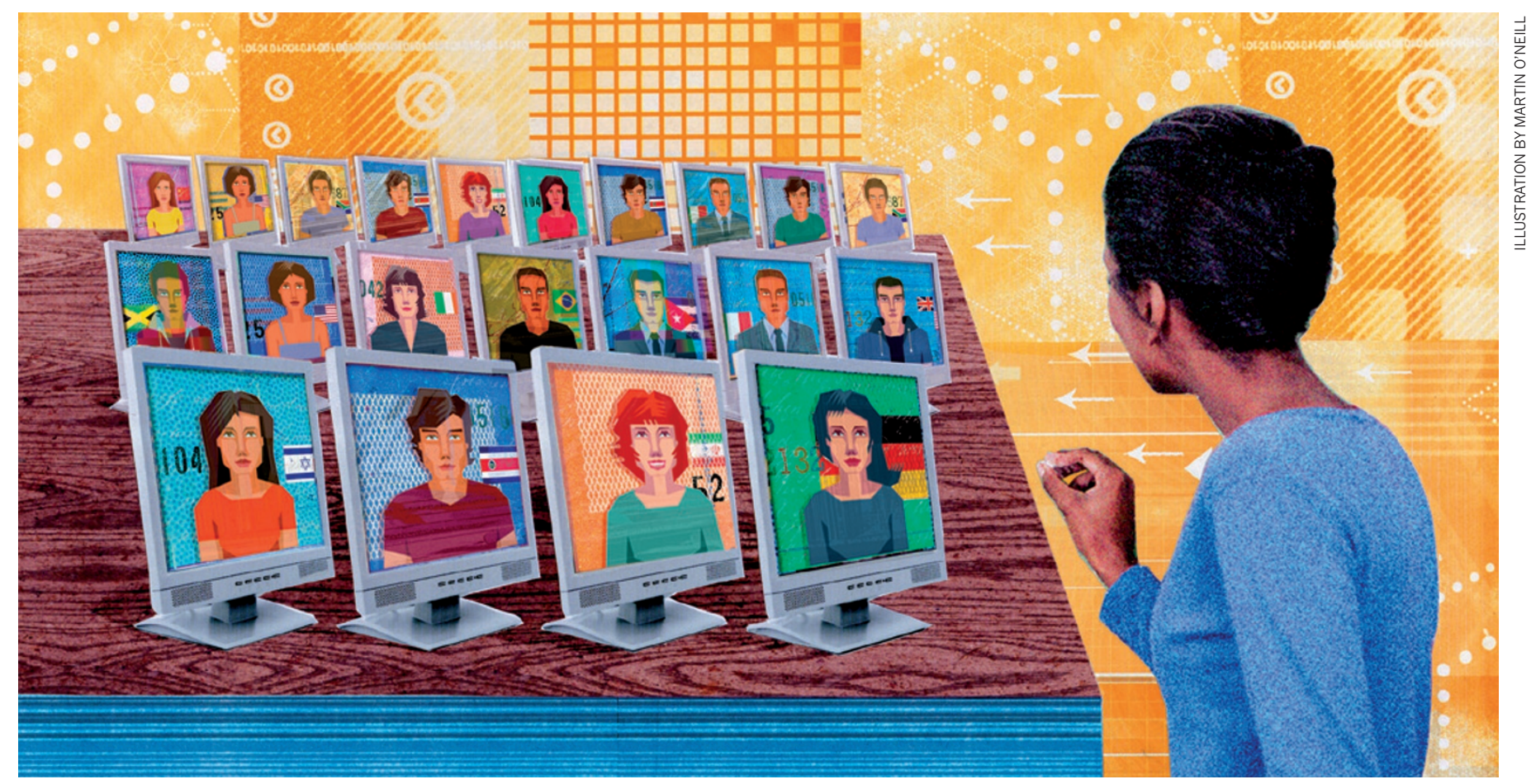

approaches, such as the modelling in the virtual world Second Life. In practice, as she shows, developing the expertise to reach the next level of a games environment is not necessarily the same as learning: obeying a set of rules does not automatically provide insight into underlying concepts or their creative application. Ironically, some approaches lose the very fun that motivates: the Shakespeare game Arden, for example, fails to capture the emotional element of the plays. In story after story of instructional technology failing to reach its transformative potential, Losh reveals that by focusing on the broadcasting of information, usually through ever more nifty gadgets, instructors and institutions risk losing sight of education as an iterative process that is based on dialogue and group reflection.

Losh concludes with suggestions for how universities might better harness technology to serve teaching. She argues that the physical classroom should be revived, because "learning benefits from embodied performances of knowledge", and using these spaces for "joyful" educational activities can offer profoundly engaging experiences.
Hackathons, for instance, bring students together for intense periods of participatory learning around common challenges, such as writing code. Likewise, Losh warns against blindly valuing innovations above clear pedagogical purpose, or eschewing tried-and-tested tools such as e-mail.

Losh falls victim to some romanticism in her recommendation that faculty members share their own research tools (say, for mapping or imaging) as part of their teaching, rather than simply give students gadgets such as clickers. This is a laudable suggestion that builds bridges between scholarship and teaching while exposing students to digital tools that have real currency in the world of research. However, such an approach could leave behind students who are not in the upper echelons of the class.
Simpler, well-executed pedagogical tools might better serve a wider audience. Merely touching genuine research tools does not ensure a good learning experience, especially if there is nothing to prepare you for it.

The War on Learning is a welcome addition to the debate and is well informed by the literature in this area, as well as cognitive psychology. That said, by largely restricting her focus to instructor and institution, Losh misses an opportunity to address the increasingly complex ecosystem of higher education, including the instructional designers, education researchers and technologists who so often work side by side with faculty members on the crafting of courses on campus and online. As this web of relationships evolves, it will redefine how instructors and institutions sustain innovative teaching through ever deeper engagement with technology.

Robert A. Lue is faculty director of HarvardX and the Derek Bok Center for Teaching and Learning at Harvard University in Cambridge, Massachusetts. e-mail:lue@harvard.edu

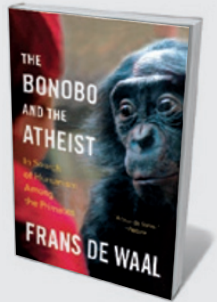

The Bonobo and the Atheist: In Search of Humanism Among the Primates Frans de Waal (W. W. Norton, 2014)

Primatologist Frans de Waal probes the roots of "human" emotions and morality in the bonobo, whose behaviours include empathy, altruism and even remorse. (See Christopher Boehm's review: Nature 495, 312; 2013.)

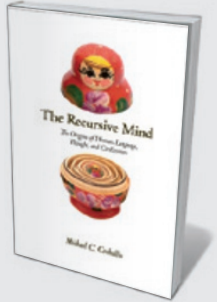

The Recursive Mind: The Origins of Human Language, Thought, and Civilization Michael C. Corballis (Princeton Univ. Press, 2014) Does language alone make us human? Psychologist Michael Corballis takes a fresh look at the origins of speech, and suggests that our ability to embed thoughts within other thoughts — recursion — gives our species the edge. 